\title{
O CAMPO DA SAÚDE DO TRABALHADOR E O CONCEITO "PROCESSO DE TRABALHO” EM MARX
}

\section{THE WORKER'S HEALTH FIELD AND THE CONCEPT "LABOR PROCESS" IN MARX}

\author{
Camila Farias Martins de Sousa ${ }^{1}$ \\ Francisco Pablo Huascar Aragão Pinheiro ${ }^{2}$ \\ Cássio Adriano Braz de Aquino ${ }^{3}$
}

\section{RESUMO}

O artigo debate o modo como o conceito "processo de trabalho", em sua acepção marxista, é apropriado pelo campo da Saúde do Trabalhador no tocante à análise dos determinantes que condicionam a produção de saúde e/ou de adoecimento laborais. Inicialmente, são apresentadas transformações conceituais e políticas que perpassaram a Medicina do Trabalho, a Saúde Ocupacional e, por fim, a Saúde do Trabalhador. É observado o modo como cada uma dessas correntes teórico-práticas define a relação entre saúde, trabalho e adoecimento, bem como são elencadas as formas de intervenção correlatas. No que tange à Saúde do Trabalhador, destaca-se a necessidade deste campo produzir conhecimento assentado numa base histórico-crítica que permita uma compreensão dialética acerca dos contextos de trabalho. Definese "processo de trabalho" a partir de Marx, considerando suas três dimensões elementares, quais sejam: objeto, instrumento e trabalho. Observa-se, ainda, a maneira como o controle exercido sobre a força de trabalho organizou-se na manufatura e na maquinaria. Tomando tais noções como suporte, demonstrase como cada uma das dimensões mencionadas pode repercutir para a saúde dos trabalhadores. São apresentados, ainda, modelos de investigação que se estruturam fundamentados no conceito "processo de trabalho".

Palavras-chave: Saúde do Trabalhador — Processo de trabalho — Marx.

\section{ABSTRACT}

The article discusses how the concept "labor process", in its marxist sense, is appropriated by the worker's health field regarding the analysis of the determinants that influence the production of health and/or work's diseases. Initially, conceptual and political transformations that permeated the Labor Medicine, the Occupational Health and, finally, the worker's health field are presented. It is observed how each of these theoretical-practical currents defines the relationship between health, work and illness, as well as the correlated ways of intervention are listed. In which concerns to the worker's health, it is highlighted the necessity of this field of to produce knowledge grounded in a historical-critical basis that allows a dialectic comprehension on the work contexts. "Labor process" is defined from Marx, considering its three 
elementary dimensions, which are: object, tool and work. It is also observed the way how the control exercised over the workforce it was organized in the manufacture and in the machinery. By taking these notions as support, it is demonstrated how each one of the mentioned dimensions can have repercussions to health of the workers. Research models that are structured from the concept of "labor process" are also presented.

Keywords: Worker's Health — Labor Process - Marx.

\section{INTRODUÇÃO}

O artigo discute como o conceito "processo de trabalho", conforme proposto por Marx, é apropriado pelo campo da Saúde do Trabalhador. Pretende-se debater sobre a utilização desta concepção para a análise dos determinantes que condicionam a produção de saúde e/ou de adoecimento laborais. Em um primeiro momento, são apresentadas mudanças conceituais e políticas que perpassaram a Medicina do Trabalho, a Saúde Ocupacional e, por fim, a Saúde do Trabalhador. Delineia-se o modo como cada uma dessas correntes teórico-práticas define a relação entre saúde, trabalho e adoecimento, assim como são enumeradas formas de intervenção pertinentes às mesmas. Em relação à Saúde do Trabalhador, destaca-se a necessidade deste campo produzir conhecimento assentado numa base histórico-crítica que permita uma compreensão dialética acerca dos contextos de trabalho.

Define-se "processo de trabalho", em sua acepção marxista, a partir de três dimensões elementares, a saber: objeto, instrumento e trabalho. Observa-se, ainda, a maneira como o controle exercido sobre a força de trabalho organizou-se na manufatura e na maquinaria.

Tomando tais noções como suporte, demonstra-se como cada elemento constitutivo do processo de trabalho pode repercutir para a saúde dos trabalhadores. Também são apresentados modelos de investigação que se estruturam fundamentados neste conceito.

Cabe ressaltar que o presente artigo traz uma discussão introdutória e não pretende esgotar todos os viéses do assunto, além de possuir um foco específico. O conceito em tela possibilita, por exemplo, proceder a análises sobre a cientifização do trabalho empreendida por Taylor e Fayol, que sistematiza as formas de controle sobre o trabalhador, desembocando nos 
atuais modelos de organização do processo produtivo, de inspiração japonesa. O enfoque aqui empreendido visa a instigar o debate entre pesquisadores $e$ profissionais interessados em construir contextos de trabalho promotores de saúde, tendo como horizonte a emancipação humana, consolidada a partir do estabelecimento de uma nova ordem societária.

\section{DA MEDICINA DO TRABALHO À SAÚDE DO TRABALHADOR: PERCURSO HISTÓRICO}

A relação entre trabalho e saúde/doença é constatada desde a antiguidade e ganha maior relevância quando do advento da revolução industrial. O trabalho fabril expunha os sujeitos a ambientes insalubres e a longas jornadas de trabalho, além de impor a manipulação de maquinário perigoso. Tais fatos favoreciam o acontecimento de acidentes e a proliferação de doenças infecto-contagiosas (MINAYO-GOMEZ; THEDIM-COSTA, 1997).

Nesse contexto, o início da intervenção nas fábricas centralizou-se na figura do médico. Esta atuação tinha um caráter biologicista e estava focada no indivíduo. Apenas eram admitidas relações unívocas e unicausais para a etiologia das doenças e para as causas de acidentes. E ainda: somente as enfermidades reconhecidas legalmente eram consideradas. Desta forma, as ações ficavam restritas ao espaço da fábrica e eram realizadas somente em torno das consequências dos agravos. A atuação do médico, muitas vezes, estava alinhada ao interesse do empresariado, que necessitava manter a mão de obra ativa e funcional.

Mendes e Dias (1991) afirmam que a Medicina do Trabalho surgiu na Inglaterra durante a primeira metade do século XIX e se espalhou por outros países em processo de industrialização, chegando mais tardiamente aos países periféricos. A atuação dos médicos, segundo essa perspectiva, tinha por função adaptar os trabalhadores às atividades que realizariam e garantir a manutenção de sua saúde física e mental.

Ainda segundo Mendes e Dias (1991), o surgimento da Saúde Ocupacional decorreu da incapacidade da Medicina do Trabalho em lidar com problemas surgidos durante a ampliação do esforço industrial demandada pela Segunda Guerra Mundial e após o conflito. A intensificação da atividade nas 
fábricas aumentou significativamente a ocorrência de acidentes e doenças ocupacionais, de modo que as ações centradas no indivíduo passaram a ser questionadas, dando espaço a outras, cujo enfoque dirigia-se ao ambiente e aos mecanismos de produção. A partir desta demanda, a Saúde Ocupacional precisou se constituir como uma disciplina multiprofissional, controlando riscos e intervindo nos ambientes de trabalho. Para tanto, fez-se necessária a incorporação de outros profissionais (além dos médicos), como engenheiros e ergonomistas.

Para Minayo-Gomez e Thedim-Costa (1997), o advento da Saúde Ocupacional representou um avanço, pois propunha a atuação interdisciplinar, admitia a multicausalidade das doenças e procurava observar as relações entre os indivíduos ou grupos, os agentes causadores das doenças e o ambiente. No entanto, alguns limites também se impunham: as ações tinham caráter pontual sobre os riscos manifestos; salientava-se o uso de equipamentos de proteção individual (diante da ausência de medidas de proteção coletiva) e procurava-se estabelecer normas e procedimentos seguros para o exercício das atividades. Estas medidas acabavam por culpabilizar os trabalhadores, tomando-os como negligentes ou ignorantes diante das iniciativas necessárias para evitar acidentes e adoecimentos.

Lacaz (2007), também discutindo a relação entre trabalho e saúde, afirma que a Saúde Ocupacional adota uma visão de causalidade dos agravos que dá primazia às condições de trabalho, sem levar em conta a contextualização histórica, social e econômica que exerce influência sobre os nexos causais existentes entre atividade laboral e processos de saúde/adoecimento. Esta visão destaca do trabalho somente aspectos detectáveis empiricamente por instrumentos das ciências físicas e biológicas (ruído, temperatura, exposição a agentes químicos e biológicos, dentre outros). Diante desta perspectiva, os prejuízos que o trabalho causaria à saúde seriam decorrentes da interação entre corpo e fatores de risco presentes no ambiente.

As intervenções, por conseguinte, procurariam adequar dimensões nocivas das condições e do ambiente de trabalho a parâmetros suportáveis para a média dos trabalhadores. Some-se a isso que os exames de admissão e periódicos funcionariam como instrumentos de seleção, de modo a excluir aqueles trabalhadores mais suscetíveis aos danos causados pelo trabalho. 
Tais concepções impediriam a Saúde Ocupacional de se debruçar sobre fatores como a organização do trabalho (que engloba, dentre outros aspectos: a duração da jornada, a divisão das tarefas, os mecanismos de controle, as forma de hierarquia), assim como tornariam sua atuação individualizada e voltada somente aos problemas de natureza orgânica. Nessa direção há "pouco espaço para a subjetividade do trabalhador, tomado como paciente e objeto da técnica, estreitando a possibilidade de apreensão das formas de adoecimento na contemporaneidade" (LACAZ, 2007, p. 759).

Mendes e Dias (1991) apontam que a Saúde do Trabalhador surge em um momento de profundas transformações sociais e econômicas iniciadas na década de 70 do século XX e aprofundadas posteriormente, dentre as quais podem ser destacadas: o deslocamento da produção industrial para países periféricos e o decorrente avanço do setor de serviços nos países de primeiro mundo; a ampliação da automação industrial e do uso da informática; bem como o surgimento de novas formas de organização do trabalho. Também são questionadas concepções hegemônicas como a determinação a-histórica, uni ou multicausal, do adoecimento.

Nesse cenário, a crítica à Saúde Ocupacional e à Medicina do Trabalho assenta-se na falta de confiança em relação aos seus procedimentos técnicos (percebidos como exclusivamente a serviço do empresariado); no questionamento aos exames admissionais e periódicos, que acabavam por gerar práticas discriminatórias; na incapacidade de lidar com a organização do trabalho e com a morbidade a ela imputada, pois as tentativas de modificação do trabalho centravam-se no ambiente e as doenças que passavam a surgir não eram facilmente medicalizáveis. Diante de tais questionamentos, a Saúde do Trabalhador definiu seu objeto como

[...] o processo saúde e doença dos grupos humanos, em sua relação com o trabalho. Representa um esforço de compreensão deste processo - como e porque ocorre - e do desenvolvimento de alternativas de intervenção que levem à transformação em direção à apropriação pelos trabalhadores, (sic) da dimensão humana do trabalho, numa perspectiva teleológica.

Nessa trajetória, a saúde do trabalhador rompe com a concepção hegemônica que estabelece um vínculo causal entre a doença e um agente específico, ou a um grupo de fatores de risco presentes no ambiente de trabalho e tenta superar o enfoque que situa sua determinação no social, reduzido ao processo produtivo, desconsiderando a subjetividade (MENDES; DIAS, 1991, p. 347). 
Minayo-Gomez e Thedim-Costa (1997) afirmam que o campo da Saúde do Trabalhador no Brasil se desenvolveu a partir da interseção das pretensões de trabalhadores, sindicatos, técnicos e pesquisadores interessados em alterar a conjuntura que permeava a saúde laboral. Estes grupos também se associavam na procura por melhores condições de trabalho; na busca pelo respeito à legislação em voga e pela implementação de políticas públicas pertinentes à área. Neste momento, as críticas ao modelo médico tradicional se fizeram presentes, bem como foi reconhecida a natureza social da produção de saber acerca do trabalho.

Tentou-se, assim, escapar da pretensão de neutralidade científica e admitir a confluência de fatores históricos e políticos para a construção de conhecimentos. Atinou-se, ainda, para a realização de ações e intervenções transformadoras, nas quais a perspectiva e o saber dos trabalhadores fossem considerados. Desta maneira, a Saúde do Trabalhador colocou-se como um campo de embate entre os diversos atores implicados com a discussão sobre a saúde e o adoecimento nos espaços de trabalho. Lacaz (2007) acrescenta que as análises efetivadas pela Saúde do Trabalhador levariam em conta a determinação social do processo de saúde/adoecimento e privilegiariam o trabalho enquanto tal, não visando somente a determinantes externos à atividade.

Há também por parte da Saúde do Trabalhador o reconhecimento de que as transformações contemporâneas pelas quais vem passando o mundo do trabalho trazem consequências à saúde (repercussões que ainda não são completamente compreendidas). Assunção (2003) aponta duas dimensões importantes e interligadas: por um lado, tem-se o processo de reestruturação produtiva; por outro, a precarização das relações de trabalho.

A primeira destas dimensões, surgida da necessidade de aumentar a produtividade, promoveu a horizontalização das empresas, de modo que as etapas de produção foram fracionadas no espaço, e levou a transferência de parte do processo fabril para países como China e Índia. Firmou-se a necessidade de trabalhadores polivalentes, hiper-qualificados e proativos. Apesar da maior autonomia aparente, este modelo aumenta as possibilidades de exploração do trabalhador: prazos são reduzidos e a competição entre os 
indivíduos é acirrada, na medida em que a responsabilidade pela produção e pelos resultados é pessoalizada. A segunda dimensão flexibilizou as formas de contratação e retirou dos sujeitos direitos historicamente conquistados (ALONSO, 2000; ALVES, 2000). Como uma consequência imediata, vê-se o enfraquecimento das organizações sindicais, de sorte que as estratégias de resistência às investidas do capital tornam-se atomizadas. É essencial, portanto, analisar as novas formas de organização do trabalho e o modo como elas incidem sobre a produção de saúde/adoecimento.

Em síntese, conforme Lacaz (2007), observa-se que a Saúde do Trabalhador atina para aspectos como: 1) a determinação social do processo de saúde/adoecimento; 2) o privilégio dado à análise do trabalho enquanto tal, não focando somente determinantes externos à atividade; 3) a importância atribuída à participação do trabalhador na construção de ações e estratégias voltadas à saúde, na medida em que este é apreendido "como agente de mudanças, com saberes e vivências sobre seu trabalho, compartilhadas coletivamente e, como ator histórico, ele pode intervir e transformar a realidade de trabalho" (Lacaz, 2007, p. 760). Além destes, podem também ser destacados: a necessidade de compreender e contextualizar as transformações que ocorreram no mundo do trabalho; e a abordagem interdisciplinar dos fenômenos, tendo em vista a importância de superar explicações parciais e atomizadas, de forma a produzir conhecimento capaz de subsidiar ações transformadoras dos contextos de trabalho.

No que tange à construção de conhecimento, Minayo-Gomez e Thedim-Costa (1997) mostram que a Saúde do Trabalhador percebeu a necessidade de desenvolver uma abordagem de investigação que se debruçasse sobre problemas ou conjuntos de problemas de forma dialética e abrangente, ao considerar a complexidade dos fenômenos por ela estudados. Nesse sentido, a noção de "processo de trabalho", oriunda do marxismo, coloca-se como importante ferramenta teórica na análise das condições que levam à produção de saúde ou de adoecimento. Tal conceito aponta que as contradições entre capital e trabalho também se manifestam no controle imposto ao próprio trabalhador, através dos diversos mecanismos de gestão do processo produtivo. Desta feita, os coletivos de trabalho passam a ser compreendidos de forma diferenciada, assim como uma multiplicidade de 
possíveis agravos passa a ser levada em consideração. Tenta-se, com isso, superar explicações simplistas sobre os determinantes dos agravos (sejam elas uni ou multicausais) que não enfocam as condições históricas e sociais envolvidas.

Gomez e Lacaz (2005, p. 799) ressaltam que "a análise dos processos de trabalho é uma ação teórico-prática potente, pois permite identificar as transformações necessárias a serem introduzidas nos locais e ambientes para a melhoria das condições de trabalho e saúde". Os autores salientam que, para alcançar esta meta, o conceito "processo de trabalho" deve ser abordado por meio de um prisma interdisciplinar. Espera-se, a partir disto, que a interligação entre relações sociais e técnicas presente na produção seja interpretada e contextualizada, além de que a subjetividade dos atores sociais envolvidos seja considerada.

O tópico a seguir situará o conceito "processo de trabalho" na perspectiva marxista. Também serão discutidas as formas de controle existentes no processo de produção a partir da divisão social do trabalho.

\section{MARX, PROCESSO DE TRABALHO E DIVISÃO SOCIAL DO TRABALHO}

Para compreender a aplicabilidade do conceito "processo de trabalho", faz-se imprescindível revisitar o pensamento de Marx e situá-lo na ontologia do ser social (LUKÁCS, 2012), cuja fundação remete necessariamente à categoria trabalho. Nesse sentido, Marx (1982) preconiza a necessidade de se compreender "processo de trabalho" como conceito originalmente independente de qualquer forma social determinada, visto que também concebe a noção de "trabalho" como vigente ao longo de toda a existência humana.

Para o autor, "trabalho" é definido como a ação intencional através da qual o homem transforma a natureza, adequando-a a seus interesses, e, concomitantemente, modifica a si mesmo. Tal ação pressupõe a vontade (previamente orientada a um fim) do sujeito que a executa, portando-se como ato intelectual. Ou seja: ao conceber a forma que será atribuída ao objeto de seu trabalho, o homem antecipa o significado da atividade, que passa a uma ação consciente e planejada. Eis a principal diferenciação estabelecida entre o 
trabalho humano cotidiano e os diversos processos de adaptação desenvolvidos pelos animais em seu intento de sobrevivência. Assim, "[...] no fim do processo do trabalho aparece um resultado que já existia antes idealmente na imaginação do trabalhador" (MARX, 1982, p. 202). Cabe notar que a noção de "processo de trabalho" integra todas as etapas constituintes da prática produtiva, desde a abstração até a concretude do produto final daí derivado.

Marx (1982) defende que na execução desta ação intencional o homem funda-se como ser eminentemente social, ao reconhecer suas necessidades de agrupamento e sociabilidade. Concebido genericamente, portanto, o trabalho representaria fonte de humanização e libertação, possibilitando inclusive o desenvolvimento do sujeito coletivo.

Este autor considera que integram o processo de trabalho três elementos simples: o próprio trabalho, o objeto de trabalho e os meios de trabalho. Entende-se por objeto a matéria sobre a qual o trabalho é exercido, podendo configurar-se como preexistente na natureza (sendo este o caso da terra, das rochas, da água, das árvores, dos animais) ou como matéria-prima (quando já experimentou qualquer modificação mediada pelo trabalho). Já os meios de trabalho (instrumentos) são concebidos como "[...] uma coisa ou um complexo de coisas, que o trabalhador insere entre si mesmo e o objeto de trabalho e lhe serve para dirigir sua atividade sobre esse objeto" (MARX, 1982, p. 203). O autor afirma que a criação e o uso dos meios ou ferramentas de trabalho são particularidades do processo de trabalho humano e o caracterizam como tal.

No final deste processo, o trabalho será objetivado, resultando em produto cujo valor de uso deverá atender às necessidades do(s) sujeito(s), já pré-concebidas no momento de sua idealização. Vale frisar que os produtos, embora surjam como resultado de determinado processo de trabalho humano, participarão de outros destes processos a fim de materializarem seus valores de uso. Por exemplo, o tecido (produto já resultante da modificação do algodão mediante instrumentos e trabalho humano) poderá servir como objeto para a produção de lençóis, sendo inserido em novo processo de trabalho, que the acarretará nova transformação. Seguindo essa mesma ideia, o machado, instrumento necessário para interpor-se entre o trabalhador e o objeto madeira, 
em dado momento configurou-se também como produto da ação humana, de modo que seu valor de uso como produto se define na medida em que há a intenção prévia de que o mesmo atue como instrumento. Nesse sentido, Marx (1982) salienta que as dimensões assumidas por objeto, instrumento e produto podem se intercambiar, de acordo com a função que exercem ao longo do processo produtivo.

O processo de trabalho compreendido em seus elementos simples, conforme apresentado até o momento, é considerado por Marx (1982, p. 208) como "[...] condição necessária do intercâmbio material entre o homem e a Natureza; condição natural eterna da vida humana [...]" - o que confirma a postura do autor quanto à defesa da centralidade do trabalho no decorrer da existência humana. Importa, então, refletir brevemente sobre os elementos que o diferem do processo de trabalho sob moldes capitalistas.

Primeiramente, cabe observar que o processo de produção capitalista indica necessariamente a unidade entre processo de trabalho e processo de valorização (ou processo de criação de valor, a partir daquilo que Marx denomina de "mais-valia"). Entenda-se que o processo de valorização dáse no âmbito da produção, visto que o valor final das mercadorias é gerado a partir da incorporação de outros valores presentes no processo produtivo (como o da matéria prima, dos meios de produção e da própria força de trabalho utilizada). Contudo, será o trabalho vivo despendido em tempo excedente ao necessário para a confecção da mercadoria que conferirá à mesma valor final gerador de lucro; ou, em outros termos, será a exploração da força de trabalho que valorizará a mercadoria.

A partir do momento em que a força de trabalho (ou "trabalho em potencial") é vendida ao capitalista, passa a pertencer-lhe. Nas palavras do autor:

Na realidade, o vendedor da força de trabalho, como o de qualquer outra mercadoria, realiza seu valor de troca e aliena seu valor de uso. Não pode obter um, sem transferir o outro. O valor do óleo vendido não pertence ao comerciante que o vendeu, e o valor de uso da força de trabalho, o próprio trabalho, tampouco pertence a seu vendedor. O possuidor do dinheiro pagou o valor diário da força de trabalho; pertence-lhe, portanto, o uso dela durante o dia, 0 trabalho de uma jornada inteira (MARX, 1982, p. 218). 
No processo de trabalho capitalista faz-se necessária a compra (para posterior consumo) tanto de fatores objetivos (matéria-prima e meios de produção) quanto do fator pessoal ("força de trabalho" ou trabalho vivo). A mercadoria "força de trabalho", assim, passa a ser controlada pelo capital tal como os demais elementos presentes no processo produtivo, sendo necessário viabilizar sua máxima utilização (desperdício mínimo) e, ao mesmo tempo, sua reprodução. Ao capitalista cabe, por exemplo, exercer controle sobre os trabalhadores, visando à utilização do objeto na exata medida necessária à produção, bem como à não destruição dos instrumentos durante o processo, a não ser que este assim o exija. Entretanto, a exploração do trabalho vivo não pode se efetivar de forma tão exacerbada, de modo que a força de trabalho venha a se exaurir com o completo desgaste do sujeito. Nesse sentido, deve o capitalista, minimamente, propiciar as condições de sobrevivência do trabalhador, garantindo-Ihe salário e períodos de repouso, por exemplo.

Segundo Marx (1982), eis as principais particularidades que envolvem o consumo da força de trabalho no processo de produção capitalista: 1) a ocorrência de grande controle do trabalhador por parte do capital; 2) o total pertencimento do produto do trabalho ao capitalista e, em consequência, o "estranhamento" do trabalhador diante dos frutos de sua atividade. Na medida em que já se definiram as funções de objeto e instrumento, interessa, para os fins desta discussão, compreender o modo como o capitalista exerce controle sobre o trabalhador, a partir da gradativa remodelagem do processo produtivo.

Ao tratar sobre "Divisão do trabalho e manufatura", Marx (1982) esclarece acerca das principais alterações que o advento da manufatura trouxe ao âmbito da produção. Entenda-se que a forma anterior de trabalho, baseada no artesanato, caracterizava-se pelo fato de o artesão exercer controle completo sobre o processo produtivo, visto que o mesmo dispunha da matériaprima, dos instrumentos, da força de trabalho e, sobretudo, do conhecimento necessário à confecção de determinado produto. As operações realizavam-se de forma sequencial, ou seja, o início de determinada operação condicionavase à finalização de outra, necessariamente anterior. Além disso, o ritmo e a jornada de trabalho definiam-se de acordo com a vontade e/ou capacidade de cada trabalhador. $O$ resultado de sua atividade, portanto, pertencia-Ihe por 
inteiro e fazia-se essencial o conhecimento sobre cada etapa necessária à fabricação da mercadoria, bem como a habilidade/aptidão para confeccioná-la.

A manufatura, ao introduzir a ideia de parcelização das atividades (indicando que cada indivíduo execute operações diferenciadas e não mais sequenciais), retira do trabalhador o controle sobre o processo produtivo como um todo. A matéria-prima, os meios de produção e a própria força de trabalho passam a ser propriedades do capitalista. A organização do trabalho é visivelmente alterada na medida em que a produção passa a subdividir-se em várias etapas justapostas - o que acarreta intensificação do ritmo de trabalho e uma crescente perda da qualificação do trabalhador, dada a simplificação das atividades previstas ao longo do processo. Diferentemente do que ocorre com o artesão, o conhecimento sobre as várias etapas da produção, bem como a habilidade relacionada a cada uma delas, não mais se configuram como pressupostos exigidos ao "trabalhador parcelar". Como consequência disso, tem-se a desvalorização do trabalhador e a diminuição de seu poder de negociação junto ao capitalista, o que leva Marx (1982, p. 404) a declarar que "na manufatura, o enriquecimento do trabalhador coletivo e, por isso, do capital, em forças produtivas sociais, realiza-se às custas do empobrecimento do trabalhador em forças produtivas individuais".

Será, entretanto, a partir da introdução de maquinários no processo produtivo (tendo por base a explosão industrial característica da Europa no século XVIII) que a exploração e o controle sobre a força de trabalho se acirrarão. Viu-se que o surgimento da manufatura provocou alterações significativas na organização do trabalho sem que isso exigisse incremento tecnológico na esfera da produção. O advento da maquinaria, por sua vez, representará necessariamente a incorporação do elemento "base técnica" ao processo produtivo, resultando numa perda gradativa da importância até então atribuída ao ofício manual e à habilidade do trabalhador que o executava. Tal inovação permitirá que o conhecimento pertencente ao trabalhador seja transferido às máquinas, de modo que as operações anteriormente realizadas pelos sujeitos passem a ser reproduzidas de forma automatizada.

Duas consequências imediatas trazidas por esta alteração podem ser notadas: 1) o trabalhador passa a ser facilmente intercambiável, dada a simplicidade quanto à operação do maquinário, que exige pouco tempo de 
treinamento para sua utilização; 2) a cadência das operações é agora determinada pelo ritmo das máquinas e não mais pela vontade dos sujeitos. Decorre daí a ampliação do controle sobre o trabalhador, ameaçado pela possibilidade iminente do desemprego, visto que suas habilidades singulares são consideradas descartáveis diante da inovação tecnológica. Resulta também disso uma intensificação exacerbada do ritmo de trabalho, extraindose do sujeito o máximo de sua capacidade laboral durante o tempo de sua permanência na fábrica. Tais efeitos são responsáveis pela maior submissão do trabalho à ordem do capital e pela redução das possibilidades de resistência por parte dos trabalhadores, já percebidas desde a manufatura.

\section{O PROCESSO DE TRABALHO COMO FERRAMENTA DE ANÁLISE}

Laurell (1978, p.60), partindo das definições expostas acima, afirma que o conceito "processo de trabalho" é pertinente para entender as conexões entre trabalho e saúde, pois, "por um lado, especifica a relação entre o trabalho, os instrumentos de trabalho e o objeto de trabalho, e por outro, abre a possibilidade de estudar o caráter histórico do trabalho" ${ }^{4}$. Some-se a isso que o "processo de trabalho" é simultaneamente técnico e social, na medida em que é por meio dele que se produzem os bens de consumo e, a partir de seu controle, é garantida a máxima produção da mais-valia, por conseguinte, do lucro e da acumulação do capital.

O princípio em torno do qual esse controle se exerce ancora-se na separação estabelecida entre execução e concepção do processo de trabalho, ou seja: ao sujeito não cabe pensar acerca de seus modos de agir, mas somente pôr em prática o que lhe é determinado, pois outros já delimitaram previamente os procedimentos necessários. Assim, alienam-se os trabalhadores da produção como um todo por meio da fragmentação do trabalho e de sua redução a pequenos movimentos em torno dos quais se impõe uma cadência. A partir disso, reduz-se o controle que o trabalhador detém sobre sua própria atividade e desqualifica-se o trabalho como fator humano subjetivo, circunscrevendo-o à sua dimensão objetiva. Tais características já se faziam presentes na manufatura e ganham maior destaque com o surgimento da maquinaria, conforme exposto acima. 
No tocante aos três elementos constituintes do processo de trabalho, Laurell (1978) tece algumas considerações. A autora afirma que, em relação ao objeto do trabalho, seja ele natural ou artificial (matéria-prima), devem ser levadas em conta suas propriedades físicas, químicas e biológicas, porque estas podem colocar em risco a saúde dos trabalhadores.

Sobre os instrumentos, Laurell (1978) afirma que devem ser visados sob dois ângulos, quais sejam: da sofisticação técnica e como expressão de relações sociais específicas. O primeiro diz respeito ao modo como o instrumento vai mediar a interação do sujeito com o objeto de trabalho. Haverá, nesse caso, implicações relativas aos riscos a que o sujeito está exposto, à autonomia que ele tem sobre a execução de suas tarefas e ao esforço físico depreendido. A segunda perspectiva pela qual 0 instrumento deve ser observado mostra como ele é construído de forma a determinar ao trabalhador uma maneira específica de trabalhar, reduzindo seu poder de decisão. Em relação às conseqüência para a saúde, Laurell (1978, p. 61) informa que "o primeiro fato está relacionado com o que parece ser o maior risco ocupacional sob o capitalismo avançado, o estresse, e o segundo aumenta em certas condições a probabilidade de acidentes".

Por fim, Laurell (1978, p. 61) atesta que "o elemento analítico mais importante do processo de trabalho para a compreensão da saúde, no entanto, é o próprio trabalho". As formas de apropriação da força de trabalho por meio do processo de trabalho estão vinculadas à obtenção das mais-valias absoluta e relativa, de modo que "as necessidades do processo de valorização do capital vão determinar a conformação específica do processo de trabalho, isto é, a forma concreta que o trabalho assume" (LAURELL, 1989, p. 1188).

O aumento da mais-valia absoluta, típica em processos produtivos que usam tecnologias simples, é exercido por meio da ampliação da jornada de trabalho, sem a proporcional compensação financeira, e pela redução dos salários, não havendo qualquer modificação na maneira como o processo de trabalho é organizado ou no maquinário utilizado. O capitalista, assim, consegue lucrar mais, pois reduz seus custos no que diz respeito à força de trabalho. Nesse caso, as conseqüências para a saúde devem-se à incapacidade de o sujeito repor a energia gasta, seja pelo menor tempo de descanso disponível, seja pela impossibilidade de adquirir os produtos 
necessários ao seu sustento em quantidade adequada às suas necessidades (alimentos, remédios, dentre outros).

A mais valia relativa se exerce pela intensificação do trabalho e da produtividade e pelo aprimoramento tecnológico do maquinário. $\mathrm{O}$ trabalhador passa a fazer mais em um mesmo montante de tempo, daí porque a ampliação da produtividade se efetiva pela imposição de um método, uma forma específica de atuar. Diante de situações como esta

[...] a introdução de uma tecnologia mais complexa implica, pelo menos até certo limite, na exposição a maiores riscos químicos e de acidentes. Os incrementos, tanto na intensidade como na produtividade, provocam situações de estresse e fadiga, causadores de mudanças fisiológicas no corpo que originam predisposições patológicas a curto e longo prazo (LAURELL, 1978, p. 62).

Laurell (1989) aponta que as investigações acerca do "processo de trabalho" costumam enfocar as relações sociais instituídas na produção da vida material, de forma a estudar as repercussões que o modo de produção capitalista tem para a saúde coletiva. Outra característica importante diz respeito à participação dos trabalhadores como sujeitos da construção do conhecimento e não somente como alvos da investigação, em consonância com o que foi exposto alhures em relação ao campo da Saúde do Trabalhador. A autora também destaca que as pesquisas fundamentadas nesse conceito, dedicadas a compreender a relação entre trabalho e saúde, apropriam-se de instrumentos metodológicos oriundos de diversas áreas, tais como as ciências sociais, a medicina e a engenharia.

Laurell (1989) afirma ainda que, nesse campo, há basicamente dois tipos de estudo, usualmente empenhados em compreender a relação entre trabalho e saúde de grupos específicos de trabalhadores. O primeiro tipo analisa os padrões de desgaste a que os trabalhadores estão submetidos em um momento delimitado. O segundo procura esclarecer como diferentes formas de processos produtivos repercutem para estes desgastes.

Noriega (1995) vê dois agrupamentos em relação a pesquisas que se apropriam do conceito "processo de trabalho". Num deles é discutida a variedade de efeitos que elementos como a organização do trabalho trazem para a saúde. Procura-se estudar pequenos grupos e postos de trabalho característicos. Noutro conjunto, assumindo a centralidade do conceito 
"processo de trabalho" para explicar a saúde dos trabalhadores, intenta-se "encontrar as relações mais gerais entre o processo de trabalho e a saúde e as formas particulares que esse processo adota na determinação do conjunto de riscos e requisitos e de conjuntos patológicos" (NORIEGA, 1995, p. 16-17).

\section{CONSIDERAÇÕES FINAIS}

As formas de compreender a relação entre trabalho e saúde/adoecimento sofreram mudanças que acompanharam as transformações sociais vividas desde o século XIX até os dias atuais: de uma visão biologicista focada no indivíduo, passando por uma determinação multicausal dos agravos, até uma visão histórico-crítica defendida pela Saúde do Trabalhador. Cabe dizer que não se compreende esse movimento como um processo evolutivo. Os diversos entendimentos convivem contemporaneamente e procuram ocupar espaços em uma arena não somente científica, mas que perpassa as lutas por um trabalho digno em meio ao modo de produção capitalista.

Diante dessa profusão de saberes, compreende-se a importância do campo da Saúde do Trabalhador ao apresentar aspectos éticos e epistemológicos relevantes para os profissionais que atuam na área. $A$ importância epistemológica se coloca quando tal perspectiva assume a historicidade e as dimensões sócio-culturais como pressupostos para a construção do saber, bem como admite que diversas disciplinas precisam dialogar a fim de possibilitarem a compreensão acerca do trabalho. O apoio ético se define ao dar um papel de relevo ao trabalhador para a formulação de conhecimento sobre o trabalho e sobre as maneiras de transformá-lo.

A tomada do conceito "processo de trabalho" pelo campo da Saúde do Trabalhador alterou a forma de se conceber e estudar o trabalho na contemporaneidade. Um dos avanços visualizados a partir de sua utilização foi a superação da etiologia ambiental dos agravos, uni ou multicausal, que teria repercussões exclusivamente biológicas. Em contraponto, afirma-se a existência de uma dimensão social implicada com o adoecimento, que se manifesta na forma como o capitalista busca a mais-valia por meio da imposição ao trabalhador de métodos e formas de proceder sua atividade, bem 
como pelo aprimoramento tecnológico das ferramentas de produção. Ao compreender que o controle exercido também se manifesta nas rotinas de trabalho previamente estruturadas, deve-se agir fortemente sobre a organização do trabalho e lutar por uma maior participação dos trabalhadores na gestão de suas atividades.

O caráter social da análise do trabalho, bem como do entendimento sobre saúde e adoecimento, não se dá meramente por tomar grupos de trabalhadores como objeto de investigação. Também não está relacionado à determinação de patologias típicas a um grupo ou a uma categoria profissional específica, comum a todos os seus integrantes e, portanto, com uma etiologia que não se reportaria somente a fatores individuais. Para se compreender 0 caráter social aqui defendido, não se deve confundir social com coletivo.

Nesse sentido, a noção "processo de trabalho" permite entender que, mesmo no indivíduo que atua isolado em seu posto, há uma relação social materializada na interação estabelecida com seu objeto de trabalho, com os instrumentos, com o método e com os procedimentos a ele impostos. Quando se considera, por exemplo, o modelo taylorista/fordista de organização produtiva, nota-se que o capitalista, ou mesmo o seu capataz, embora não estejam materialmente presentes ao lado do trabalhador em todos os momentos da produção, fazem-se notar ao estabelecerem uma jornada de trabalho; um ritmo cadenciado para a consecução da atividade; uma maneira específica para a realização de uma tarefa; um gesto a ser executado; um modo de uso do maquinário; formas de controle e vigilância das ações, dentre outros.

É necessário notar que tal controle exercido sob o trabalhador ganha contornos diferenciados diante dos vários modelos de estruturação do trabalho. O gerenciamento baseado no que se convencionou chamar de toyotismo apregoa a necessidade de um trabalhador hiper-qualificado e polivalente, capaz de intervir nos processos produtivos e garantir sua qualidade. Desse empregado não se requer somente o gesto, mas toda uma implicação subjetiva, em um processo contínuo de identificação com a empresa. Ampliamse as formas de controle, na medida em que as estruturas de supervisão e condução do processo desenvolvidas pele taylorismo são introjetadas pelo trabalhador. Aparentemente há uma maior autonomia; entretanto, ao 
responsabilizar o sujeito pela realização dos objetivos da empresa, ampliam-se as formas de exploração. Isto se deve ao fato de que as metas da empresa são incutidas no trabalhador como metas pessoais a serem alcançadas (TOLEDO, 2003).

Faz-se relevante entender que os vários modelos de estruturação produtiva do trabalho não são estanques, podem conviver dentro de uma mesma organização e, muitas vezes, se hibridizam. Contudo, em todos os casos, a produção da mais-valia é a mola propulsora de tais projetos e a alienação do trabalhador diante do processo produtivo, a chave para seu sucesso.

Obviamente, a relação do trabalhador com estes ditames está longe de ser pacífica. A Ergonomia (FALZON, 2007) há muito demonstrou que entre a tarefa prescrita e a atividade efetivamente realizada pelo trabalhador existe uma série de reveses não previstos pelas gerências. O sujeito e os coletivos de trabalho ativamente se apropriam das limitações a eles impostas e ainda se adaptam às variações e situações imprevisíveis que a organização não conseguiu antecipar. A Psicodinâmica do Trabalho (DEJOURS; ABDOUCHELI; JAYET, 1994), por sua vez, demonstrou como os coletivos criam estratégias conjuntas para superar o sofrimento correlato à realização do trabalho. A Clínica da Atividade (CLOT, 2007) mostrou como os grupos de trabalho constroem culturas profissionais próprias que regulam a ação em paralelo às determinações da organização e tentam, desta forma, superar as amputações às possibilidades de ação.

Vale destacar que as questões tematizadas no presente artigo podem suscitar a interlocução entre as várias disciplinas que se dedicam ao estudo da saúde dos trabalhadores. Diante de aspectos distintos da realidade, visados pelas mais diversas abordagens, o conceito "processo de trabalho" coloca-se como fio condutor de diálogo capaz de produzir a síntese dialética necessária para compreender a complexidade que envolve a relação saúdetrabalho-adoecimento. 


\section{REFERÊNCIAS}

ALONSO, L. E. Trabajo y posmodernidad: el empleo débil. Madrid: Editorial Fundamentos, 2000.

ALVES, G. O novo (e precário) mundo do trabalho: reestruturação produtiva e crise do sindicalismo. São Paulo: Boitempo, 2000.

ASSUNCAO, A. Á. Uma contribuição ao debate sobre as relações saúde e trabalho. Ciência e saúde coletiva, São Paulo, vol. 8, n. 4, p. 1005-1018, 2003.

CLOT, Y. A função psicológica do trabalho. Petrópolis: Vozes, 2007.

DEJOURS, C.; ABDOUCHELI, E; JAYET, C. Psicodinâmica do trabalho. Contribuições da escola dejouriana à análise da relação prazer, sofrimento e trabalho. São Paulo: Atlas, 1994.

FALZON, P. Ergonomia. São Paulo: Edgard Blücher, 2007.

GOMEZ, C. M.; LACAZ, F. A. de C. Saúde do trabalhador: novas-velhas questões. Ciência e saúde coletiva, Rio de Janeiro, vol.10, n.4, p. 797-807, Oct./Dec. 2005.

LACAZ, F. A. de C. O campo Saúde do Trabalhador: resgatando conhecimentos e práticas sobre as relações trabalho-saúde. Cadernos de. Saúde Pública, Rio de Janeiro, vol. 23, n.4, p. 757-766, abr. 2007.

LAURELL, A, C. Proceso de trabajo e salud. Cuadernos Políticos, México, D.F, n. 17, p. 59-79, jul./set. 1978.

Social analysis of collective health in Latin America. Social Science \& Medicine, v. 28, n. 11, p. 1183-1191, 1989.

LUKÁCS, G. Para uma ontologia do ser social I. São Paulo: Boitempo, 2012.

MARX, K. O capital: crítica da economia política. Livro 1: o processo de produção do capital. São Paulo: Difel, 1982.

MENDES, R.; DIAS, E. C. Da medicina do trabalho à saúde do trabalhador. Revista de Saúde Pública, São Paulo, vol. 25, n. 5, p. 341-349, Oct. 1991.

MINAYO-GOMEZ, C.; THEDIM-COSTA, S, M. da F. A construção do campo da saúde do trabalhador: percurso e dilemas. Cadernos de Saúde Pública, Rio de Janeiro, vol. 13 (supl. 2), p. S21-S32, 1997.

NORIEGA, Mariano. La realidad latinoamericana frente a los paradigmas de investigación en salud laboral. In: Revista Salud de los Trabajadores / Mexico, 1995, vol. 3, p. 4-19. 
TOLEDO, E. de la G. La flexibilidad del trabajo en América Latina. In: TOLEDO, E. de la G. (coordinador). Tratado Latinoamericano de Sociologia del

Trabajo. México: FCE/Flacso - Sede México, 2000 (p. 148-170).

${ }^{1}$ Camila Farias Martins de Sousa é graduada em Serviço Social pela Universidade Estadual do Ceará (2005). Possui especialização em Serviço Social pela Universidade de Brasília (2010). Atualmente, cursa Mestrado em Educação Brasileira na Universidade Federal do Ceará (UFC) e atua como assistente social junto à Pró-Reitoria de Assuntos Estudantis da mesma Instituição. E-mail: camila.farias@ufc.br

2 Francisco Pablo Huascar Aragão Pinheiro é graduado em Psicologia pela Universidade Federal do Ceará - UFC (2005). Possui Mestrado em Psicologia pela UFC e cursa Doutorado em Educação Brasileira nesta mesma instituição. Atualmente, é psicólogo da Coordenadoria de Qualidade de Vida no Trabalho da UFC. E-mail: pablohap@icloud.com

${ }^{3}$ Cássio Adriano Braz de Aquino é graduado em Psicologia pela Universidade Federal do Ceará (1989) e em Administração pela Universidade de Fortaleza (1986), possui Suficiência Investigadora em Psicologia Social — Universidad Complutense de Madrid (2000), é Mestre em Administração pela Universidade Federal da Paraíba (1994) e Doutor em Psicologia Social - Universidad Complutense de Madrid (2003). Possui estágio Pós-doutoral na Universidad Complutense de Madrid (2009). Atualmente, é professor adjunto da Universidade Federal do Ceará, Coordenador Acadêmico e Vice-Diretor do Centro de Humanidades da UFC. E-mail: brazdeaquino@gmail.com

${ }^{4}$ Todas as citações dos textos em língua estrangeira referenciados foram traduzidas pelos autores.

RECEBIDO EM: novembro/2013

APROVADO EM: dezembro/2013 